\title{
A Case of Pyoderma Gangrenosum with Myelodysplastic Syndrome
}

\author{
Jae Won Ha, Ji Eun Hahm, Kang Su Kim, Sang Seok Kim, Chul Woo Kim \\ Department of Dermatology, Kangdong Sacred Heart Hospital, Hallym University College of Medicine, Seoul, Korea
}

\begin{abstract}
Dear Editor:
Pyoderma gangrenosum (PG) is a rare inflammatory ulcerative skin disease associated with systemic disease. Several cases have shown a relationship between PG and hematologic malignancies such as myelodysplastic syndrome (MDS). A 43-year-old man visited the department of plastic surgery because of a painful skin lesion on his suprapubic area since 1 month. He was highly obese (height, $177 \mathrm{~cm}$; weight, $130 \mathrm{~kg}$ ) and diagnosed as having diabetes mellitus 5 years ago. Physical examination revealed a solitary, large, erythematous round plaque, $15 \times 5 \mathrm{~cm}$ in size, with a raised border and surrounding violaceous patches (Fig. 1). Initial laboratory data revealed normal white blood cell (WBC) count $(5,680 / \mu \mathrm{l})$, anemia (red blood cell [RBC] count, $2.3 \times 10^{6} / \mu \mathrm{l}$; hemoglobin level, $8.5 \mathrm{~g} / \mathrm{dl}$; hematocrit concentration, $25 \%)$, and low platelet count $(84,000 / \mu \mathrm{l})$. In the plastic surgery department, wound debridement, split-thickness skin graft placement, and surgical biopsy were performed. Biopsy revealed diffuse infiltration of neutrophils and lymphocytes in the epidermis, dermis, and subcutaneous fat tissue. Clinical and histopathological findings indicated PG (Fig. 2A). After debridement, the wound had become larger than initial size. He was referred to the dermatological department for cotreatment with methylprednisolone $(125 \mathrm{mg} / \mathrm{d})$ and cyclosporine $(300 \mathrm{mg} / \mathrm{d})$. During the treatment, he showed marked hematologic abnormalities and aggravated pancytopenia (WBC count, $1,800 / \mu \mathrm{l}$; RBC count, $2.63 \times 10^{6} / \mu \mathrm{l}$; hemoglobin level, $8.5 \mathrm{~g} / \mathrm{dl}$; and platelet count, $31,000 / \mu \mathrm{l})$. Thus, bone marrow biopsy was performed. The numbers
\end{abstract}

of erythroid precursors and megakaryocytes increased, and granulocytic precursors relatively decreased. Accordingly, he was diagnosed as having MDS and referred to an oncologist for chemotherapy. For 5 months, he was treated with cyclosporine $(300 \mathrm{mg} / \mathrm{d})$ and methylprednisolone, with gradual tapering of the steroid dose (Fig. 2B). As a result, the PG lesion almost healed, but the MDS persisted. PG is a rare inflammatory, non-infectious, ulcerating skin disorder with an unknown pathogenesis, although immune complex-mediated neutrophil hyperactivity has been proposed ${ }^{1-3}$. Histopathological findings are not diagnostic but help to exclude other differential diagnoses. It usually shows neutrophilic and mixed lymphocytic infiltrations in the dermis ${ }^{1,3}$. No confirmatory diagnostic test is available, and diagnosis relies on clinical and histological correlation ${ }^{2}$. Immunosuppressive agents such as high-dose steroids, cyclosporine, and azathioprine can be used as treatment for PG. PG was frequently associated with systemic diseases such as inflammatory bowel disease, Crohn disease, Bechet disease, and hematologic malignancies ${ }^{1-5}$. MDS is a hematologic malignancy that shows a neoplastic change in myeloid stem cells. It may also be associated with $\mathrm{PG}^{3-5}$. The pathogenesis of the association between PG and MDS is unknown. Some hypotheses have been proposed, including immunologic mediated processes involving the product of autoantibodies to cutaneous antigen and the deposition of immune complex. Patients with MDS have abnormal laboratory findings such as anemia, thrombocytopenia, and pancytopenia. Our patient showed aggravated abnormal

Received May 12, 2017, Revised July 31, 2017, Accepted for publication August 4, 2017

Corresponding author: Sang Seok Kim, Department of Dermatology, Kangdong Sacred Heart Hospital, Hallym University College of Medicine, 150 Seongan-ro, Gangdong-gu, Seoul 05355, Korea. Tel: 82-2-2224-2285, Fax: 82-2-474-7918, E-mail: hj2456hj@naver.com ORCID: https://orcid.org/0000-0001-9717-9710

This is an Open Access article distributed under the terms of the Creative Commons Attribution Non-Commercial License (http://creativecommons.org/ licenses/by-nc/4.0) which permits unrestricted non-commercial use, distribution, and reproduction in any medium, provided the original work is properly cited.

Copyright (C) The Korean Dermatological Association and The Korean Society for Investigative Dermatology 

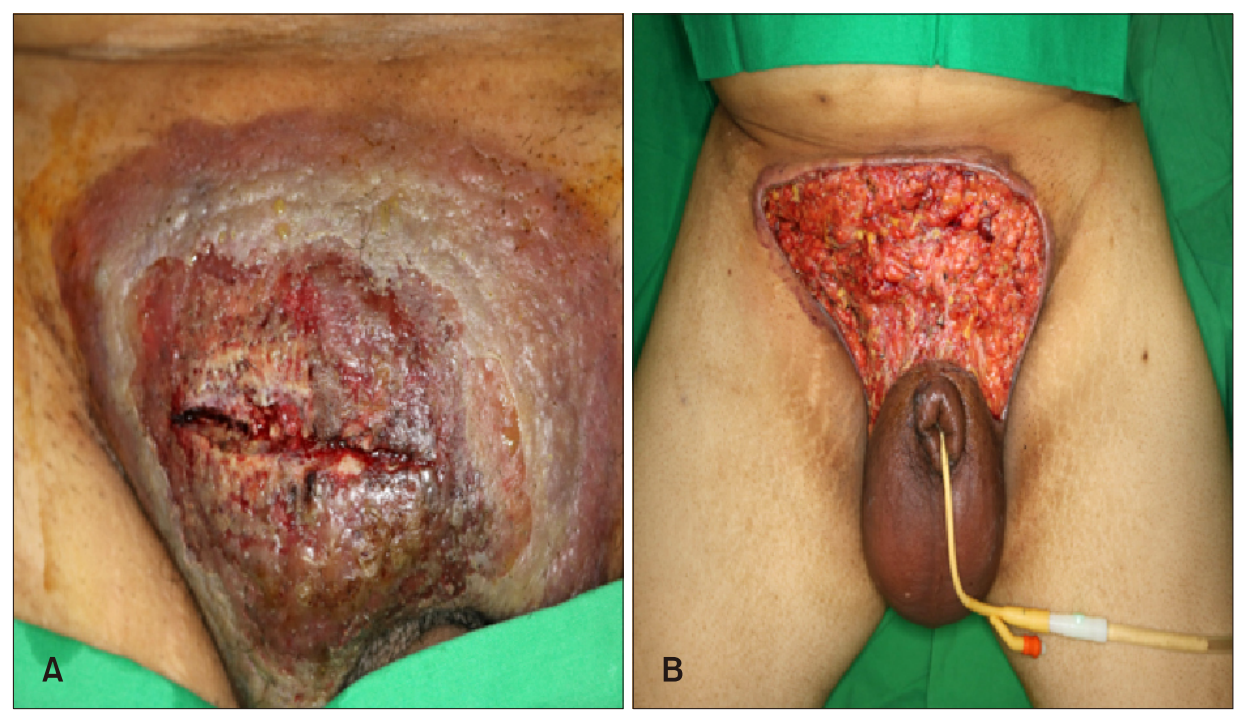

Fig. 1. (A) $15 \times 5 \mathrm{~cm}$ sized, solitary large erythematous round plaque with raised border and surrounding violaceous patches on the suprapubia area. (B) $25 \times 20 \mathrm{~cm}$ sized lesion, after necrotic wound debridement.
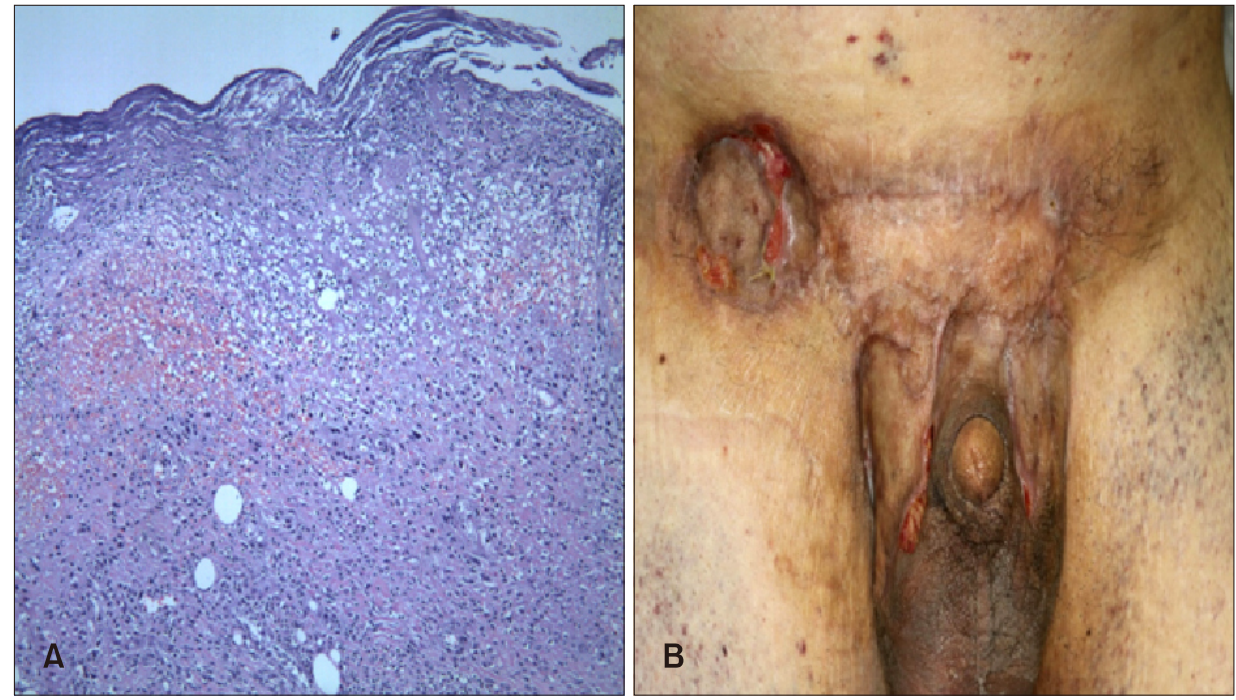

Fig. 2. (A) Skin biopsy specimen showed dermal and perivascular infiltration with several neutrophils and lymphohistiocytes (H\&E, $\times 40)$. (B) Almost healed skin lesion following 5 month of cyclosporine and steroid therapy. laboratory findings during the diagnosis and treatment of PG. Based on the bone marrow biopsy result, we made a diagnosis of MDS. Dermatologists should diagnose PG expeditiously because of its rapid clinical course and association with other systemic diseases. Patients with PG should be evaluated for hematologic abnormalities. If abnormal findings are present, early bone marrow biopsy is needed to detect hematological malignancies.

\section{CONFLICTS OF INTEREST}

The authors have nothing to disclose.

\section{REFERENCES}

1. Lee JI, Park HJ, Lee JY, Cho BK. A case of pyoderma gangrenosum with ulcerative colitis treated with mesalazine. Ann Dermatol 2010;22:422-425.

2. von den Driesch P. Pyoderma gangrenosum: a report of 44 cases with follow-up. Br J Dermatol 1997;137:1000-1005.

3. Yamanaka K, Kuniyuki S, Maekawa N, Yoshida Y, Teshima $\mathrm{H}$. Pyoderma gangrenosum with myelodysplastic syndrome treated with analogous bone marrow transplantation. Acta Derm Venereol 2009;89:105-106.

4. Litvak D, Kirsner RS, Pakdaman NN, Federman DG. Pyoderma gangrenosum and myelodysplastic syndrome. South Med J 2000;93:923-925.

5. Koca E, Duman AE, Cetiner D, Buyukasik Y, Haznedaroglu IC, Uner A, et al. Successful treatment of myelodysplastic syndrome-induced pyoderma gangrenosum. Neth J Med 2006;64:422-424. 